Www.jmscr.igmpublication.org

ISSN (e)-2347-176x ISSN (p) 2455-0450

crossrefDOI: https://dx.doi.org/10.18535/jmscr/v7i1.98

Journal Of Medical Science And Clinical Research

IGM Publication

An Official Publication of IGM Publication

Original Research Article

\title{
Epidemiology of Perforated Peptic Ulcer - A Regional Study
}

\section{Authors \\ Dr Dinesh Singh Chauhan ${ }^{1 *}$, Dr Sanjay Kumar Bhasin ${ }^{2}$}

${ }^{1}$ MBBS, M.S, Senior Resident, Department of Surgery, Government Doon Medical College Dehradun, India

${ }^{2}$ MBBS, D.H.A, M.S, FMAS, FAIS Professor, Department of Surgery, Government Medical College

Jammu, India

*Corresponding Author

Dr. Dinesh Singh Chauhan

Department of Surgery, Government Doon Medical College, Dehradun, Uttarakhand, India

Phone (or Mobile) No.:+917579016317, Email:drdinesh0225@gmail.com

\begin{abstract}
Background: Perforated peptic ulcer is a serious complication of peptic ulcer disease and patients with perforated peptic ulcer often present with acute abdomen that carries high risk for morbidity and mortality.

Methods: This is a retrospective study conducted at Government Medical College Jammu on seventy eight patients who underwent surgery for benign perforated peptic ulcer from November 2013 to December 2014. Data from 78 patients was retrieved, compiled, summarised and analysed statistically using frequency distribution and percentage proportion.

Results: Seventy eight patients were included in the study. There were $25(32.05 \%)$ patients in $5^{\text {th }}$ decade and $17(21.79 \%)$ patients in $4^{\text {th }}$ decade with a male to female ratio of 38:1. The condition among Hindu patients was (75.64\%) as compared to Muslims (24.35\%) and majority of the patients were illiterate $(71.79 \%)$ with low socioeconomic status $(94.87 \%)$ and belonged to rural setup (55.13\%). Patients with $O$ positive blood group were most affected (38.46\%) followed by B positive blood group (30.76\%). 29.49\% patients were taking NSAIDS for musculoskeletal pain. Out of 78 patients 64 patients (82.05\%) were smokers, 40 patients (51.28\%) used to consume alcohol, 37 patients (47.43\%) used to both drink and smoke.
\end{abstract}

Conclusions: It is concluded that in this region of the country perforated peptic ulcer is more common in Hindu males in their fourth and fifth decade, belonging to a low socioeconomic status, residing in rural areas and have habit of both smoking and drinking.

Keywords: Perforated peptic ulcer, Helicobacter pylori, Omentopexy.

\section{Introduction}

Word 'peptic' is derived from the Greek term 'peptiko's' meaning related to digestion ${ }^{[1]}$. Peptic ulcer disease is a group of disorder characterized by the presence of ulcers in any position of gastrointestinal tract exposed to acid in sufficient concentration and duration. Although these ulceration most commonly occur in the stomach (Gastric ulcer), or small intestine (duodenal ulcer) 
yet this entity also includes Barrett ulcer of the lower oesophagus.

Johan Mikulicz-Radecki (1850-1905), often referred to as the first surgeon who closed a Perforated peptic ulcer by simple closure, said: 'Every doctor, faced with a perforated peptic ulcer of the stomach or intestine, must consider opening the abdomen, sewing up the hole, and averting a possible inflammation by careful cleansing of the abdominal cavity ${ }^{\text {[2] }}$.

Surprisingly enough, treatment has not changed much since, still consisting of primary closure of the perforation by a single stitch suture and a convenient tag of adjacent omentum on top of this ${ }^{[3]}$. Although this therapy sounds very simple perforated peptic ulcer still remains a dangerous surgical condition, associated with high morbidity and mortality, not to be underestimated. The pathogenesis of Peptic ulcer disease may best be considered as representing a complex scenario involving an imbalance between defensive (mucus-bicarbonate layer, prostaglandins, cellular renovation, and blood flow) and aggressive factors (hydrochloric acid, pepsin, ethanol, bile salts, some medications, etc. $)^{[4]}$. In recent years, Helicobacter pylori infection and NSAIDs have been identified as the two main causes of peptic ulcer ${ }^{[5]}$. The use of crack cocaine has also led to an increase in perforated peptic ulcer, but with a different underlying mechanism, since perforated peptic ulcer secondary to the use of crack cocaine is caused by ischemia of the gastric mucosa, and treatment of these perforations does not require acid reducing definitive surgery ${ }^{[6]}$.

Duodenal ulcer is the predominant lesion of the western population, whereas gastric ulcers are more frequent in oriental countries, particularly in Japan. Gastric ulcers have a higher associated mortality and a greater morbidity resulting from haemorrhage, perforation and obstruction ${ }^{[5]}$. Perforated peptic ulcer used to be a disorder mainly of younger patients (predominantly males), but recently the age of Perforated peptic ulcer patients is increasing (predominantly females) ${ }^{[7]}$. The current peak age is $40-60$ years $^{[7]}$. Until the discovery of the role of $\mathrm{H}$. pylori in gastric and peptic ulcers by Barry J. Marshall and Robin Warren in 1982, stress and life style factors were believed to be the most important factors contributing to Peptic ulcer disease and perforated peptic ulcer ${ }^{[8]}$. H. pylori infection can be held responsible in more than $90 \%$ of duodenal ulcers and in up to $80 \%$ of gastric ulcers ${ }^{[5],[8]}$. According to the Maastricht III consensus report, first line treatment for $H$. pylori infection should be triple therapy which should compromise a proton pump inhibitor (PPI) plus clarithromycin plus amoxicillin or metronidazole ${ }^{[5],[9]}$. Monotherapy by just giving antibiotics has proven not to be successful $(<30 \% \text { eradication rate })^{[5]}$.

The present study is being carried out with intent to study various epidemiological factors responsible for perforated peptic ulcer in this part of the country.

\section{Methods}

The study was conducted in Government Medical College and Hospital Jammu (Jammu and Kashmir) for a period of one year, w.e.f 01-112013 to 31-10-2014.

The diagnosis of peptic ulcer perforation was made by History, Clinical Examination and Radiological Investigation and was confirmed at laparotomy. Patients who were diagnosed as peptic ulcer perforation, both gastric and duodenal, and were negative for malignancy were only included in the present study.

On admission a detailed History and thorough Clinical Examination was recorded as per the attached Performa. The patients were subjected to various investigations which include routine haemogram, urine analysis, blood urea, serum creatinine, serum electrolytes, radiological examination, ECG, Blood grouping, $\mathrm{X}$ ray chest and USG abdomen. A special attempt was made to look into various precipitating factors which led to perforations. The data from the past one year was retrieved, compiled, summarised and analysed statistically using frequency distribution and percentage proportion. 


\section{Results}

Data of 78 patients presented with peptic ulcer perforation during this period is being presented here.

Maximum incidence of peptic ulcer perforation was seen in $5^{\text {th }}$ decade followed by $4^{\text {th }}$ decade. There were $25(32.05 \%)$ patients in $5^{\text {th }}$ decade and $17(21.79 \%)$ patients in $4^{\text {th }}$ decade. There were 12 $(15.38 \%)$ patients in $6^{\text {th }}$ decade, $10(12.82 \%)$ patients in $7^{\text {th }}$ decade and $7(8.97 \%)$ patients in $3^{\text {rd }}$ decade. No patient with peptic ulcer perforation presented in $1^{\text {st }}$ decade and a very few patients presented in $2^{\text {nd }}(3.84 \%)$ and $8^{\text {th }}(5.12 \%)$ decade. (Table 1).

Out of 78 patients $76(97.43 \%)$ were males and 2 patients $(2.56 \%)$ were females. Males dominated the series in this study and male to female ratio was 38:1. The males were in the age group of mainly $4^{\text {th }}$ and $5^{\text {th }}$ decade. (Table 2 ).

Out of 78 patients involved in the study, 35 patients (44.87\%) belonged to urban setup whereas 43 patients $(55.13 \%)$ belonged to rural setup. (Table 3 ).

In this study 59 patients $(75.64 \%)$ belonged to Hindu religion whereas 19 (24.35\%) patients were Muslim. (Table 4) and 22 patients (28.20\%) were literate whereas 56 patients $(71.79 \%)$ were illiterate. (Table 5).

In this study 74 patients $(94.87 \%)$ belonged to Lower socioeconomic status and 4 patients (5.13\%) belonged to middle class. (Table 6).

Although the patients presented round the year but the frequency of presentation was different at different periods of the year. Maximum incidence of the peptic ulcer perforation cases were seen in October i.e. 14 (17.94 \%) followed by May 11(14.10\%) and November $9(11.53 \%)$. (Table 7).

30 patients $(38.46 \%)$ were having $\mathrm{O}+\mathrm{ve}$ blood group and one patient (1.28\%) belonged to $\mathrm{O}-\mathrm{ve}$ blood group ; 24 patients (30.76\%) belonged to B +ve blood group whereas one patient (1.28\%) belonged to B -ve blood group ; 14 patients (17.94\%) were having A +ve blood group ; whereas blood group $\mathrm{AB}$ accounted for the rest of
8 patients $(10.25 \%)$ out of which 7 patients (8.97\%) were $\mathrm{AB}+\mathrm{ve}$ and one patient (1.28\%) belonged to $\mathrm{AB}$-ve blood group. (Table 8).

There were a number of patients who were taking drugs. Twenty three patients $(29.49 \%)$ gave a history of taking NSAIDS. These drugs were being given to them for joint and muscle pain. (Table 9).

$64(82.05 \%)$ out of 78 patients were smokers, 40 patients $(51.28 \%)$ used to consume alcohol, 37 patients $(47.43 \%)$ used to both drink and smoke, whereas; 11 patients (14.10\%) were neither smokers nor alcoholic. (Table 10).

Table 1: Age wise distribution

\begin{tabular}{|l|c|c|}
\hline Age in years & No. of patients & Percentage \\
\hline $11-20$ & 3 & 3.84 \\
\hline $21-30$ & 7 & 8.97 \\
\hline $31-40$ & 17 & 21.79 \\
\hline $41-50$ & 25 & 32.05 \\
\hline $51-60$ & 12 & 15.38 \\
\hline $61-70$ & 10 & 12.82 \\
\hline $71-80$ & 4 & 5.12 \\
\hline Total & 78 & \\
\hline
\end{tabular}

Table 2: Sex distribution

\begin{tabular}{|c|c|c|}
\hline Sex & Number of patients & Percentage \\
\hline Male & 76 & 97.43 \\
\hline Female & 2 & 2.56 \\
\hline
\end{tabular}

Table 3: Region.

\begin{tabular}{|l|c|c|}
\hline Region & Number of patients & Percentage \\
\hline Rural & 43 & 55.13 \\
\hline Urban & 35 & 44.87 \\
\hline Total & 78 & \\
\hline
\end{tabular}

Table 4: Religion

\begin{tabular}{|l|c|c|}
\hline Religion & Number of patients & Percentage \\
\hline Hindu & 59 & 75.64 \\
\hline Muslim & 19 & 24.35 \\
\hline Total & 78 & \\
\hline
\end{tabular}

Table 5: Educational status

\begin{tabular}{|l|c|c|}
\hline Educational & Number of patients & Percentage \\
\hline Literate & 22 & 28.20 \\
\hline Illiterate & 56 & 71.79 \\
\hline Total & 78 & \\
\hline
\end{tabular}


Table 6: Socioeconomic status

\begin{tabular}{|l|c|c|}
\hline $\begin{array}{l}\text { Socioeconomic } \\
\text { status }\end{array}$ & $\begin{array}{c}\text { Number of } \\
\text { patients }\end{array}$ & Percentage \\
\hline Lower class & 74 & 94.87 \\
\hline Middle class & 4 & 5.13 \\
\hline Upper class & Nil & Nil \\
\hline Total & 78 & \\
\hline
\end{tabular}

Table 7: Seasonal variation

\begin{tabular}{|l|c|c|}
\hline Month & Number of cases & Percentage \\
\hline January & 5 & 6.41 \\
\hline February & 5 & 6.41 \\
\hline March & 5 & 6.41 \\
\hline April & 2 & 2.56 \\
\hline May & 11 & 14.10 \\
\hline June & 6 & 7.69 \\
\hline July & 7 & 8.97 \\
\hline August & 5 & 6.41 \\
\hline September & 5 & 6.41 \\
\hline October & 14 & 17.94 \\
\hline November & 9 & 11.53 \\
\hline December & 4 & 5.12 \\
\hline Total & 78 & \\
\hline
\end{tabular}

Table 8: Blood group

\begin{tabular}{|l|c|c|}
\hline Blood group & Number of patients & Percentage \\
\hline A & 14 & 17.94 \\
\hline B & 25 & 32.05 \\
\hline AB & 8 & 10.25 \\
\hline O & 31 & 39.74 \\
\hline Total & 78 & \\
\hline
\end{tabular}

Table 9: Ulcerogenic drugs

\begin{tabular}{|l|c|c|}
\hline Drug & Number of patients & Percentage \\
\hline No drug intake & 55 & 70.51 \\
\hline $\begin{array}{l}\text { Patients taking } \\
\text { NSAIDS }\end{array}$ & 23 & 29.49 \\
\hline $\begin{array}{l}\text { Patients taking } \\
\text { steroids }\end{array}$ & Nil & Nil \\
\hline Total & 78 & \\
\hline
\end{tabular}

Table 10: Habits

\begin{tabular}{|l|c|c|}
\hline Habits & Number of patients & Percentage \\
\hline Smoker & 64 & 82.05 \\
\hline Alcoholic & 40 & 51.28 \\
\hline Both & 37 & 47.43 \\
\hline Nil & 11 & 14.10 \\
\hline
\end{tabular}

\section{Discussion}

The incidence of peptic ulcer perforation varies in different parts of the world. In this study maximum incidence of peptic ulcer perforation was seen in $5^{\text {th }}$ decade $(\mathrm{n}=25,32.05 \%)$ followed by $4^{\text {th }}$ decade $(\mathrm{n}=17,21.79 \%)$. In the study of Subedi S K, Afaq A, Adhikary S, Niraula S R,
(2007) of one hundred and forty-five patients who underwent Graham's patch repair for perforated duodenal the mean age was 45.99 years $^{[10]}$. In the study of Aijaz A. Memon, Afsar Ali Bhutto, Ghulam Shabir Shaikh. (2007) the prevalence of perforation was highest in patients of 40-59 years of age ${ }^{[11]}$. In the study of Nuhu A, Kassama Y (2008 the mean age of presentation was $45.49+/$ 14.46 years $^{[12]}$.

In this study out of 78 patients 76 patients $(97.43 \%)$ were males and 2 patients $(2.56 \%)$ were females making a male to female ratio of $38: 1$. It would mean that not only is peptic ulcer less common in women but when present, the liability to perforation is considerably less than in men. In the study of Aijaz A. Memon, Afsar Ali Bhutto, Ghulam Shabir Shaikh. (2007) out of 86 patients, 81 were males and 5 were females with a male to female ratio of $16.2: 1^{[11]}$.

In this study out of 78 patients involved, 43 patients $(55.13 \%)$ belonged to rural setup whereas 35 patients $(44.87 \%)$ belonged to urban setup. Further in this study most of the patients 56 (71.79\%) were illiterate whereas 22 patients $(28.08 \%)$ were literate (received education up to $5^{\text {th }}$ standard and were able to read and write). 59 patients $(75.64 \%)$ belonged to Hindu religion whereas 19 (24.35\%) patients were Muslim. This is in accordance with the study conducted by Rigopoulos A, RAMBOIUS. I, Georgescu .I (2011) in which they concluded that with an average incidence of 35 cases per year ulcer perforation was more common in patients coming from rural areas and were illiterate ${ }^{[12]}$. In the study conducted by Kassim Trayem Hayef \& Adnan Yassin Abdul-Wahab (2011) it was seen that out of hundred patients included in the study the disease was more common in rural areas (58\%) than in urban areas $(42 \%)^{[13]}$.

According to the socioeconomic status of the patients in this study, 74 patients $(94.87 \%)$ were poor i.e. lower socioeconomic status and 4 patients $(5.13 \%)$ belonged to middle class. In a study conducted by Gabriel R_Nzarubara (2005) it was observed that lower socio-economic group 
and a crowded and unsanitary living environment predisposes to high incidence of peptic ulcer disease and subsequent perforation ${ }^{[14]}$. Moshe Schein (2010) in his study also concluded that perforated peptic ulcers are common in socioeconomically disadvantaged or stressed populations worldwide ${ }^{[15]}$.

The seasonal variation seen in this study is that the commonest cases presented in autumn season. Gujar N, Chougule P, Bhosale S, Mane H et.al. (2012) conducted a prospective study involving 50 patients of perforated duodenal ulcer and peak incidence in this study was observed in the months of September, October, November and December $^{[16]}$.

The history of intake of ulcerogenic drugs was seen in only 23 patients $(29.48 \%)$. Patients using these drugs were older, with more pre-existing medical conditions and had larger ulcers than those not taking drugs. Koo Jarley, Ngam Y.K. and Lam S.K. (1983) studying hospital records of Hong Kong city during the decade 1970-80 found an increase in incidence of duodenal ulcer perforations which they found to be age related and they concluded the cause to be a increased life span and increased use of non steriod antiinflammatory drugs mainly in the elderly ${ }^{[17]}$.

In this study majority $(38.46 \%)$ of the patients were blood group $\mathrm{O}$ positive followed by blood group B positive patients which constituted 24\% of the patients. Sondashi KJ, Odimba BFK, Kelly P (2011 in their at University Teaching Hospital (UTH), Lusaka Zambia found that the commonest blood group was group O+ $(33.2 \%)^{[18]}$. Dr. Murtaza A Calcuttawala, Dr. Daksha S Nirhale (2013) in their study observed that O+ve blood group was most common in patients with peptic ulcer perforation ${ }^{[19]}$.

In this study $64(82.05 \%)$ out of 78 patients were smokers, 40 patients $(51.28 \%)$ used to consume alcohol, 37 patients $(47.43 \%)$ used to both drink and smoke whereas 11 patients $(14.10 \%)$ were neither smokers nor alcoholic. In the study of Canoy DS, Hart A R, Todd C J (2002) in Norfolk, United Kingdom to find out Epidemiology of duodenal ulcer perforation there were 25 (36.8\%) smokers ${ }^{[20]}$. Fawaz Chikh Torab, Mohamed Amer, Fikri M. Abu-Zidan, et.al. (2009) in their study found smoking to be a common risk factor for peptic ulcer perforation ${ }^{[21]}$.

\section{Conclusion}

From the available data of the present study and literature on the subject it is concluded that the epidemiological parameters with respect to age, sex, rural-urban difference, socioeconomic status and seasonal variations are in accordance with the available studies in literature. However, relation of usage of ulcerogenic drugs, peptic ulcer disease and subsequent development of peptic ulcer perforation could not be established, probably due to lack of health education amongst the patients in the study group. Furthermore, the study concludes that the incidence of peptic ulcer perforation is more in Hindu religion than Muslims in this part of the world. It is concluded that the peptic ulcer perforation more so duodenal ulcer perforation is a disease of middle aged males with preponderance in Hindu Religion in this part of the world.

\section{Declarations}

Funding: No source

Conflict of interest: No conflict of interest

Ethical approval: Taken

\section{References}

1. Zittel TT, Jehle EC, Becker HD. Surgical management of peptic ulcer disease today: indication, technique and outcome. Langenbecks Archives of Surgery 2000; 385:84-96.

2. Schein M. To drain or not to drain? The role of drainage in the contaminated and infected abdomen: an international and personal perspective. World Journal of Surgery 2008; 32:312-321.

3. Rayner HH. Treatment of perforated peptic ulcer. Lancet 1930; ii:107-108 
4. Ramakrishnan K, Salinas RC. Peptic ulcer disease. American Family Physician 2007; 76:1005-1012.

5. Sivri B. Trends in peptic ulcer pharmacotherapy. Fundamental and Clinical Pharmacology 2004; 18:23-31.

6. Lagoo S, McMahon RL, Kakihara M, Pappas TN, Eubanks S. The sixth decision regarding perforated duodenal ulcer. Journal of the Society of Laparoendoscopic Surgeons 2002; 6: 359-368.

7. Lunevicius R, Morkevicius M. Systematic review comparing laparoscopic and open repair for perforated peptic ulcer. British Journal of Surgery 2005; 92:1195-1207.

8. Ahmed N. 23 years of the discovery of Helicobacter pylori: is the debate over? Annals of Clinical Microbiology and Antimicrobials 2005; 4:17.

9. Malfertheiner P, Megraud F, O'Morain C, et al Current concepts in the management of Helicobacter pylori infection: the Maastricht III Consensus Report. Gut. 2007 Jun; 56(6):772-81. Epub 2006 Dec 14.

10. Subedi SK, Afaq A, Adhikary S, Niraula SR, Agrawal CS. Factor's influencing mortality in perforated duodenal ulcer following emergency surgical repair. Journal of Nepal Medical Association 2007; 46: 31-5.

11. Aijaz A. Memon, Afsar Ali Bhutto, Ghulam Shabir Shaikh, Amanullah Jokhio and Quratul-ain Soomro. Journal of Liaquat University of Medical and Health Sciences (JLUMHS) 2009; 08 No.01

12. Rigopoulos. A, Ramboiu.P, Georgescu. I. A critical evaluation of surgical treatment of perforated peptic ulcer 2011;37:2

13. Kassim Trayem Hayef and Adnan Yassin Abdul Wahab: Basrah Journal of Surgery 2011; 17.
14. Gabriel R Nzarubara: African Health Sciences 2005; 5: 73-78.

15. Moshe Schien: Schein common sense emergency abdominal surgery 2009; 157166.

16. N Gujar,P Chougule,S Bhosale, H Mane, $S$ Paighan, $V$ Balachandran Long-Term Results Of Simple Closure Of Perforated Duodenal Ulcer In The Era Of Proton Pump Inhibitor And Anti-H.Pylori Therapy_The Internet Journal of Surgery. 2012 Volume 28 Number 3.

17. Koo Jarley, Ngam Y.K. and Lam S.K. Aetiology of peptic ulcer. Ann Acad Med Singapore. 1983 Oct; 12(4):498-506.

18. KJ Sondashi, BFK Odimba, P Kelly A Cross-sectional Study on Factors Associated With Perforated Peptic Ulcer Disease in Adults Presenting to UTH, Lusaka Medical Journal of Zambia - Vol 38, No 2 (2011)

19. Murtaza A, Daksha S. Perforated Duodenal Ulcer Emergency Pattern Medical Journal of Dr. D.Y. Patil University 2014; 7: 1-2

20. Canoy DS, Hart AR, Todd CJ. Digestive and Liver Disease. 2002; 34:322-7.

21. Fawaz Chikh Torab, Mohamed Amer, Fikri M. Abu-Zidan, Frank James Branicki. Asian Journal of Surgery 2009; 32: 95-101. 